\title{
Problematic Internet Users and Psychiatric Morbidity in a Sample of Egyptian Adolescents
}

\author{
Mona Reda ${ }^{1}$, Menan Rabie ${ }^{2}$, Nesrin Mohsen ${ }^{2}$, Aisha Hassan ${ }^{3}$ \\ ${ }^{1}$ Institute of Childhood Postgraduate Studies, Ain Shams University, Cairo, Egpyt \\ ${ }^{2}$ Institute of Psychiatry, Ain Shams University, Cairo, Egpyt \\ ${ }^{3}$ Ministry of Health, Ahmed Maher Hospital, Alexandria, Egpyt \\ Email: menan74@yahoo.com
}

Received May $8^{\text {th }}, 2012$; revised June $7^{\text {th }}, 2012$; accepted July $10^{\text {th }}, 2012$

\begin{abstract}
Background: A growing body of research suggests that Problematic Internet use is becoming more common in society as on-line usage increases everyday. Is psychiatric morbidity common among problematic internet users? What are the characteristics of these patients? Methods: 501 adolescents (295 males), 11 18 years old, recruited from 2 private (group 1) and 2 governmental schools (group 2). All were subjected to A Psychiatric sheet, An Informative designed questionnaire, Fahmy and El Sherbiny's Social Classification Scale, Young internet addiction test (IAT), and Mini International Neuropsychiatric Interview for children and adolescents (MINI KID). Results: Comparison between the two groups in regard places of use of internet, number of computers available, money spent on internet activities, parental knowledge of use, duration of use and purpose of use, revealed significant differences. Problematic internet use was more frequent in group 1, while internet addiction was more frequent in group 2 . A significant relation was found between IAT score and social phobia, specific phobia and oppositional defiant disorder, and a highly significant relation with generalized anxiety disorder and ADHD. Female sex, horror movies and internet problematic use are independent predictors of psychiatric morbidity. Male sex, private schools, high social class are independent predictors for internet use problems in our sample. Conclusion: This study revealed that Egyptian adolescents are at high risk for problematic internet use and to a lesser extent Internet Addiction. Adolescents with Problematic Internet use were more prone to psychiatric disorders (social phobia, specific phobia, oppositional defiant disorders, generalized anxiety disorder and ADHD).
\end{abstract}

Keywords: Problematic Internet Use; Psychiatric Morbidity; Adolescents

\section{Introduction}

Within the context of the development of new information and communication technologies, the Internet has become a means of accessing information, interpersonal communication and entertainment. Its widespread use has important repercussions at the individual, social, technological and economic levels (Munoz et al., 2010). In Egypt, more than 80\% of Internet Café clients were young people, $60 \%$ of the youth surveyed spent their time chatting, $20 \%$ browsing pornography sites, $12 \%$ conducting business or scientific work and $8 \%$ visiting political sites (UNDP \& INP, 2010).

This study was initiated in light of the relatively high prevalence of Egyptian Internet users coinciding with the new era of Problematic internet use allover the world. Dysfunctional use of such technology probably leads to changes in the psychological profiles of the young population and may interfere with the person's social life, school work, or job-related tasks at work, enhancing withdrawal from the real world, and at certain occasions constituting a predisposing factor for the appearance of psychiatric disorders.

Problematic Internet Use (PIU) has received increasing

"The submitted manuscript contains original unpublished work and is not being submitted for publication elsewhere at the same time. There is no conflict of interest. research attention; a consistent definition of this construct has not been currently applied. PIU has been proposed as a novel entity of dysfunctional behavioral patterns similar to those identified within the spectrum of impulse control disorders. Worldwide, the prevalence of PIU among adolescents and young adults has been observed to range between $2 \%$ and $11 \%$ (Aboujaoude, 2010).

Researchers have established that the disorder develops into a dependency for the person; they experience tolerance and withdrawal affects (Ferris, 2003). Similar to what an addict of any other substance goes through, and becomes just as isolated as them. Rejecting the real world and adopting the Internet as a route of escape to a mood altering experience (DeAngelis, 2000).

Given the recent expansion and the expected increase in internet availability and usage in the coming years, it is important that healthcare professionals be informed about this behavior and its associated problems; internet addiction is a newly emergent disorder. It has been found to be associated with a variety of psychiatric disorders (Ko et al., 2012) as well as, subjective distress, functional impairment and Axis I psychiatric disorders (Shapira et al., 2000).

\section{Hypothesis of the Study}

The hypothesis of the study was that adolescents experiencing problematic internet use have psychiatric morbidity. 


\section{Aim of the Study}

Primarily explore current psychiatric morbidity in problematic adolescent internet users and its potential risk factors.

\section{Design and Methods}

\section{Participants}

Cross sectional design was applied for purpose of the study; all data were collected during the first semester of academic year 2010-2011. The study was approved by the ethical committee of the Institute of Postgraduate Studies, Ain-Shams University, as well as, school administrations and parents of participants, after careful explanation of the study and its objectives, a written consent of approval to participate was obtained from parents as well as students after ensuring confidentiality of data.

Source of the sample was randomly selected students from 16 classes in four high schools, two private international schools (moderate to high annual fees) and two governmental schools (no annual fees) all students were encouraged to participate in the study $(\mathrm{N}=539)$. No exclusion criteria, including demographic and/or socioeconomic characteristics, for the study participants were applied.

\section{Assessments}

Ain Shams University Psychiatric sheet: that includes items related to demographic information (age, sex, school grade), family history, past history, psychiatric symptoms and examination.

Informative designed questionnaire: to assess patterns of internet use, including questions to identify the following: the location of internet access: 1) one's own home portal; 2) a friend's home portal; and 3) internet café portal. The scope of internet sites accessed included: 1) educational (a. study, b. information, c. research); 2) entertainment (a. email, b. chatting, c. online games); 3) other specific uses to be named. Also duration and frequency of internet use, as well as parents' awareness of internet use.

Fahmy and El Sherbiny's Social Classification Scale (Fahmy \& El Sherbini, 1988): the classification is based on 5 parameters: education of the father, education of the mother, income, crowding index and sanitation. The parameter yields a total score. Score of 25 - 30 is considered high social class 1 , score of 20 - 25 is considered middle \& high middle social class 2 , score of $15-20$ is considered low social class 3 , score of 14 or lower is considered very low social class 4 .

The Young Internet Addiction Test (IAT): was used to detect problematic internet use and internet addiction (Young, 1999). The IAT is a 20 items questionnaire on which the person is asked to rate the items on a 5 point scale. It can be used in clinical settings to screen for internet abuse among adults and adolescents. It classifies internet users into three groups: Average Users who have complete control over their internet activities, problematic users who experience frequent problems due to their internet activities and Internet Addicts who experience significant problems due to their dependence on internet activities. The IAT is a valid and reliable instrument that can be used in research (Widyanto \& Mcmurran, 2004). It was translated to Arabic in the current study. The reliability of the translated version was tested in a pilot study of 50 subjects (age and sex matching control); Cronbach's Alpha based on standardized items was .814 .

The Mini International Neuropsychiatric Interview for children and adolescents (MINI KID) (Sheehan et al., 1998) was used to identify psychiatric morbidity. The MINI KID is a structured clinical interview for the major Axis I disorders. It was developed jointly by psychiatrists and clinicians in the United States and Europe, for DSM-IV and ICD-10 psychiatric disorders. It is divided into 22 modules designated by letters, each corresponding to psychiatric diagnostic category. With an administration time of approximately 15 minutes, it was designed to meet the need for a short but accurate structured psychiatric interview for multicenter clinical trials and epidemiology studies and to be used as a first step in outcome tracking in non research clinical settings. The reliability of the translated version was tested in a pilot study of 100 subjects; Cronbach's Alpha based on standardized items was .795 .

\section{Procedure}

The study proper was performed at the Institute of Childhood Postgraduate Studies, Ain Shams University Hospitals in the period from the beginning of January 2009 to the end of June 2010. The students were subjected to the following:

Informed consent was obtained from all students before they participated in the study.

Each student was interviewed by one of the researchers by the use of Ain Shams University Psychiatric sheet. This took about 15 - 30 minutes. An Informative designed questionnaire and Fahmy and El Sherbiny's Social Classification Scale were given to each student so that he fills them in, which took about 5 - 10 minutes. Then the student was submitted to The MINI KID for Psychiatric diagnosis. This step took about $15-25$ minutes.

\section{Data Analysis}

The collected data were analyzed by the Statistical Package for Social Sciences (SPSS), version 15 and expressed as following: Chi-square test was used to compare qualitative variables between groups, Fisher exact test was used instead of chi-square when one or more expected cell $<5$. Unpaired t-test was used for comparison of quantities variables, binary logistic regression analysis was used to find out the most significant independent predictors affecting outcome by using backward Likelihood ratio technique. Statistical analyses were conducted with the application of the SAS version 9.0 (SAS Institute Inc., USA) software package, $P$-value $(P)$ of $P$ value $>.05$ insignificant, $\leq .05$ was the criterion for significance and $P<.01$ highly significant.

\section{Results}

The sample of the study constituted of 501 adolescent students recruited from 2 private schools (group 1) and 2 governmental schools (group 2). The interview and all assessments were conducted in presence of a research team member, with response rate $(100 \%) .295$ male students (59\%), 206 female students $(41 \%)$ with no significant difference $\left(\mathrm{X}^{2}=0, P \geq .05\right)$, aged between 11 - 18 years old, with highly significant difference in money spent on internet activities between two groups, as well as social class according to Fahmy and El-Sherbiny Social Classification Scale $\left(\mathrm{X}^{2}=127, P \geq .001\right),\left(\mathrm{X}^{2}=14, P \geq .001\right)$ respectively as shown in Table $\mathbf{1}$.

Comparison between two groups in regard places of use of internet (Table 2), number of computers available, parental 
Table 1.

Comparison between both groups as regard general data.

\begin{tabular}{|c|c|c|c|c|c|}
\hline Variables & Private $(\mathrm{N}=251)$ & Governmental $(\mathrm{N}=250)$ & Chi square & $P$-value & Significance \\
\hline Age & $\begin{array}{c}\text { Mean + SD } \\
15+1.5\end{array}$ & $\begin{array}{c}\text { Mean + SD } \\
14.1+1.4\end{array}$ & .7 & $>.05$ & NS \\
\hline Gender & $\mathrm{N}(\%)$ & $\mathrm{N}(\%)$ & 0 & $>.05$ & NS \\
\hline Female & $104(41.4 \%)$ & $103(41.2 \%)$ & & & \\
\hline Male & $147(58.6 \%)$ & $147(58.8 \%)$ & & & \\
\hline Spend & & & 127 & $<.001$ & HS \\
\hline$<5$ & $41(16.3 \%)$ & $144(61.3 \%)$ & & & \\
\hline $6-10$ & $82(32.7 \%)$ & $72(30.6 \%)$ & & & \\
\hline$>11$ & $117(46.6 \%)$ & $19(8.1 \%)$ & & & \\
\hline NA & $11(4.4 \%)$ & $15(6.0 \%)$ & & & \\
\hline Social class & & & 14 & $<.001$ & HS \\
\hline Very low & $31(12.3 \%)$ & $37(14.8 \%)$ & & & \\
\hline Low & $8(3.2 \%)$ & $14(5.6 \%)$ & & & \\
\hline Middle & $5(2.0 \%)$ & $20(8.0 \%)$ & & & \\
\hline
\end{tabular}

Table 2.

(a) Comparison between both groups in regard to internet use; (b) Comparison between both groups in regard to purpose of internet use.

(a)

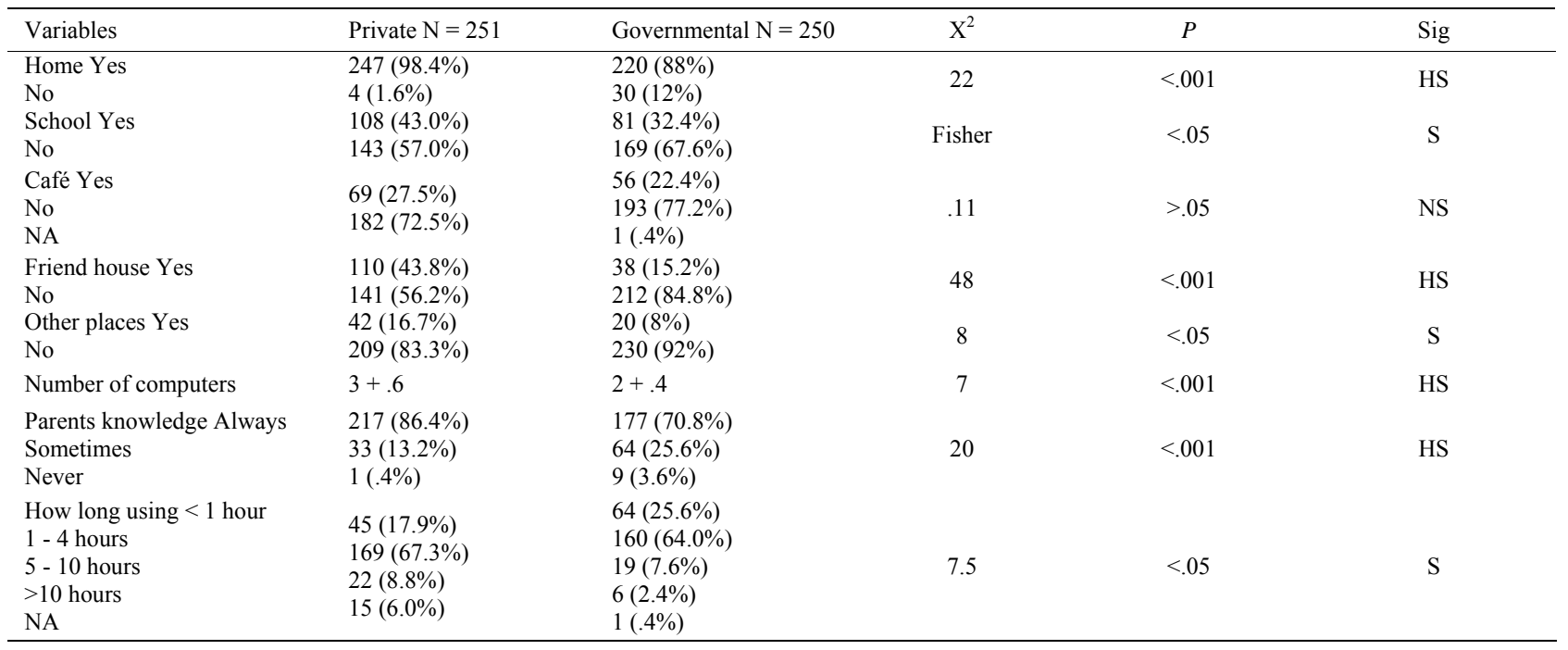

(b)

\begin{tabular}{|c|c|c|c|c|c|c|}
\hline \multirow{3}{*}{ Educational } & Study & $157(62.5 \%)$ & $107(42.8 \%)$ & 19 & $<.001$ & HS \\
\hline & Information & $176(70.1 \%)$ & $156(62.4 \%)$ & Fisher & $<.05$ & $\mathrm{~S}$ \\
\hline & Research & $186(74.1 \%)$ & $168(67.2 \%)$ & Fisher & $<.05$ & $\mathrm{~S}$ \\
\hline \multirow{3}{*}{ Entertainment } & E-mail & $192(76.5 \%)$ & $121(48.4 \%)$ & Fisher & $<.05$ & $\mathrm{~S}$ \\
\hline & Chat & $207(82.5 \%)$ & $135(54.0 \%)$ & Fisher & $<.001$ & HS \\
\hline & On line games & $143(56.9 \%)$ & $163(65.2 \%)$ & Fisher & $<.05$ & $\mathrm{~S}$ \\
\hline
\end{tabular}

knowledge of use, duration of use and purpose of use, revealed significant differences all in favor of group 1.

Applying IAT indicated numerical difference in regard to problematic internet use. It was more frequent in group 1, while internet addiction was more frequent in group 2, with significant difference in favor of group 1 (private schools) $\left(\mathrm{X}^{2}=5\right.$, $P \leq .05)$ as shown in Table 3 . For statistical reasons, both groups were summated and named problematic internet users (PIU) group.

Testing for Frequency of internet use and duration of internet use was significant in favor of students with problematic use $\left(\mathrm{x}^{2}\right.$ $\left.=20.47, p \geq .05, \mathrm{x}^{2}=21.35, p \geq .001\right)$ respectively.

Using MINI-KID showed no significant difference between the two groups in regard to psychiatric disorders, still when using Fisher extract test a significant relation was found between IAT score and social phobia, specific phobia and oppositional defiant disorder $(P \leq .05)$ in all, and a highly significant relation with generalized anxiety disorder and Attention deficit hyperactive disorder $(P \leq .001)$ in all, as shown in Table 4. 
Table 3.

Comparison between both groups as regards IA score.

\begin{tabular}{|c|c|c|c|c|}
\hline & Private $\mathrm{N}=251$ & Govern, $\mathrm{N}=250$ & Chi square & $P$-value \\
\hline No IA & $184(73.3 \%)$ & $202(80.8 \%)$ & & \\
\hline Some & $66(26.3 \%)$ & $45(18.0 \%)$ & 5 & $<.05$ \\
\hline Signifi & $1(.4 \%)$ & $3(1.2 \%)$ & & \\
\hline
\end{tabular}

Table 4.

Psychiatric disorders in relation to IA problematic use.

\begin{tabular}{|c|c|c|c|c|}
\hline & \multicolumn{2}{|c|}{ IA problematic use } & \multirow{2}{*}{$P$-value } & \multirow{2}{*}{ Significance } \\
\hline & No & Yes & & \\
\hline Depression & $19(6.7 \%)$ & $5(5.9 \%)$ & $>.05$ & NS \\
\hline Dysthemia & $22(7.8 \%)$ & $9(10.5 \%)$ & $>.05$ & NS \\
\hline Panic & $35(12.6 \%)$ & $14(17.1 \%)$ & $>.05$ & NS \\
\hline Agrophobia & $61(21.9 \%)$ & $21(25.6 \%)$ & $>.05$ & NS \\
\hline Anxiety & $85(30.7 \%)$ & $29(35.8 \%)$ & $>.05$ & NS \\
\hline Social phobia & $14(5.1 \%)$ & $8(10 \%)$ & $<.05$ & $\mathrm{~S}$ \\
\hline Specific phobia & $27(9.8 \%)$ & $14(17.5 \%)$ & $<.05$ & $\mathrm{~S}$ \\
\hline $\mathrm{OCD}$ & $13(4.7 \%)$ & $6(7.5 \%)$ & $>.05$ & NS \\
\hline Generalized anxiety & $21(7.7 \%)$ & $15(18.8 \%)$ & $<.001$ & HS \\
\hline ADHD & $5(1.8 \%)$ & $2(2.5 \%)$ & $>.05$ & NS \\
\hline ADHD hyperactivity & $5(1.8 \%)$ & $1(1.3 \%)$ & $>.05$ & NS \\
\hline ADHD combined & $1(.4 \%)$ & $4(5 \%)$ & $<.001$ & HS \\
\hline Oppositional defiant & $69(25.3 \%)$ & $30(37.5 \%)$ & $<.00$ & $\mathrm{~S}$ \\
\hline
\end{tabular}

In an attempt to identify a relation between PIU and presence of a psychiatric morbidity in the whole studied group, watching movies (especially horror movies) was found to be of significant relation to the occurrence of a psychiatric disorder $(P$ $\leq .05)$.

Using binary logistic regression test indicated that female sex, horror movies and internet problematic use are independent predictors of psychiatric morbidity. On the other hand males, private schools, high social class are considered independent predictors for internet use problems (problematic/addiction) in our sample. As shown in Table 5.

\section{Discussion}

For adolescents, the Internet serves as an inexpensive, readily accessible platform for social interaction (Paul \& Bryant, 2005) and leisurely activities (Dannon \& Iancu, 2007). With the growing wealth of literature on PIU among adolescents, researchers attempted to investigate the psychiatric morbidity in PIU, and its possible risk factors.

Table 5.

Relation between psychiatric disorders, internet problematic use and different variables by logistic regression.

\begin{tabular}{|c|c|c|c|}
\hline Independent predictors & Beta-coefficient & $P$-value & Odd's $(95 \% \mathrm{CI})$ \\
\hline \multicolumn{4}{|c|}{ Psychiatric disorder } \\
\hline Female sex & .98 & $<.05$ & $1.7(.4-7.8)$ \\
\hline Horror movies & .45 & $<.05$ & $1.2(.4-6)$ \\
\hline IA (positive problem) & .42 & $<.05$ & $1.1(.1-7)$ \\
\hline Govern school & .19 & $>.05$ & $1.01(.2-4.9)$ \\
\hline \multicolumn{4}{|c|}{ Internet problematic use } \\
\hline Male sex & .56 & $<.05$ & $1.3(.3-10.8)$ \\
\hline Private school & .33 & $<.05$ & $1.1(.3-11.7)$ \\
\hline High social class & .25 & $<.05$ & $1(.4-7)$ \\
\hline
\end{tabular}

Although the internet enhances psycho-social development, still pathological internet use encouraged researchers to monitor this phenomena, European prevalence reported between 1 and 9\% (Pallanti et al., 2006; Siomos et al., 2008; Villella et al., 2010), Middle Eastern prevalence at between 1 and 12\% (Ghassemzadeh et al., 2008; Canbaz et al., 2009; Canan et al., 2010). And prevalence in Asia reported between 2 and 18\% (Ko et al., 2007; Park et al.; 2008, Song et al., 2010). Variation in figures can be explained by the different criteria used to identify internet problematic use and/or addiction (pathological use), which was evident in our study as $22.1 \%(\mathrm{n}=111)$ showed to have problematic Internet use, and $.8 \%(n=4)$ proved to have Internet addiction, in the current work both (problematic and addictive users) were referred to as PIU.

Excessive and pathological Internet users are inevitably making regular and intense use of the Internet, with regard to both the frequency and duration of each Internet session, especially for accessing e-mail, chat rooms, and Internet games (Cak \& Leung, 2004), which consistent with the current work, as students with problematic internet users tend to login more frequent and stay online for longer duration, as it is a major contributor in defining PIU.

Psychiatric morbidity in adolescents with PIU has been identified in several researches, (Ha et al., 2006; Ko et al., 2008), in the current study PIU subjects showed higher tendency in showing anxiety disorders i.e., social phobia, specific phobia as well as generalized anxiety disorder, which is in agreement with previous studies (Shapira et al., 2000; Milani et al., 2009; Akin \& Iskender, 2011). These findings could be explained by the speculation that online social networking gives adolescents the chance to form virtual friends they can't face in real world which positively affect social and moral knowledge among adolescents.

Attention-deficit/hyperactivity disorder (ADHD), hostility, depression, were correlated in other study to internet addiction 
(Ko et al., 2009), in the current study we could identify ADHD $(P \geq .001)$ but failed to correlate with depression, this could be explained by the outnumber of 295 male (59\%) to 206 females $(41 \%)$. PIU is known for the multiple windows with different activities, rapid responses and immediate reward which may resembles symptoms of ADHD.

Using logistic regression to identify independent predictors to psychiatric disorder; female gender and horror movies were related, on the other hand, males, high social class, private school were independent predictors to PIU, gender difference was proven in previously conducted studies (Ceyhan, 2008; Frangos \& Sotiropoulos, 2011). These factors should be taken with caution, and larger scale studies should be conducted, as although in Egypt gender gap regarding internet use is 59\% males and $41 \%$ females (MCIT, 2010), still several barriers exist such as basic computer illiteracy and high price of internet service.

In conclusion PIU is not an uncommon problem among Egyptian adolescents, potential risk factors identified in this work include: high social class, male gender and availability of access. Anxiety disorders and ADHD are the most prevalent comorbid psychiatric disorders.

\section{Limitations}

The researchers admit having difficulties in obtaining higher sample size due to refusal of few schools to participate, secondary to denying approval for psychiatric assessment as well as reluctance of adolescents to participate. Another limitation is excluding smart phones as sample included students from low economic families'.

\section{Acknowledgements}

Special thanks go to the subjects of the study, without them this study wouldn't be possible.

\section{REFERENCES}

Aboujaoude, E. (2010). Problematic internet use: An over view. World Psychiatry, 9, 85-90.

Akin, A., \& Iskender, M. (2011). Internet addiction and depression, anxiety and stress. International online journal of educational sciences, 3, 138-148

Canan, F., Ataoglu, A., Nichols, L. A., Yildirim, T., \& Ozturk, O. (2010). Evaluation of psychometric properties of the Internet addiction scale in a sample of Turkish high school students. Cyberpsychology, Behavior, and Social Networking, 13, 317-320.

doi:10.1089/cyber.2009.0160

Canbaz, S., Sunter, A. T., Peksen, Y., \& Canbaz, M. A. (2009). Prevalence of the pathological Internet use in a sample of Turkish school adolescents. Iranian Journal of Public Health, 38, 64-71.

Ceyhan, A. A. (2008). Predictors of problematic Internet use on Turkish university students. CyberPsychology \& Behavior, 11, 363-366. doi: $10.1089 / \mathrm{cpb} .2007 .0112$

Chak, K., \& Leung, L. (2004). Shyness and locus of control as predictors of Internet addiction and Internet use. CyberPsychology \& Behavior, 7, 559-570.

Dannon, P., \& Iancu, I. (2007). Internet addiction. Harefuah, 146, 549553.

DeAngelis, T. (2000). American Psychological Association. Is internet addiction real? URL (last checked 20 November 2003). http://www.apa.org/monitor/aproo/addiction.html

Fahmy, S. I., \& El Sherbini, A. F. (1988). Determining simple parameters for social classification for health researchers. The Bull of the
High Institute of Public Health, 10, 95-108.

Frangos, C. C., \& Sotiropoulos, I. (2011). Problematic Internet Use among Greek university students: An ordinal logistic regression with risk factors of negative psychological beliefs, pornographic sites, and online games. Cyberpsychology, Behavior, and Social Networking, 14, 51-58. doi:10.1089/cyber.2009.0306

Ferris, J. R. (2003). Internet addiction disorder: Cause, symptoms, and consequences. URL (last checked 20 November 2003). http://www.rider.edu/ suler/psycyber/cybaddict.html

Ghassemzadeh, L., Shahraray, M., \& Moradi, A. (2008). Prevalence of Internet addiction and comparison of Internet addicts and non-addicts in Iranian high schools. CyberPsychology \& Behavior, 11, 731-733. doi:10.1089/cpb.2007.0243

Ha, J. H., Yoo, H. J., Cho, I. H., Chin, B., Shin, D., \& Kim, J. H. (2006). Psychiatric comorbidity assessed in Korean children and adolescents who screen positive for Internet addiction. Journal of Clinical Psychiatry, 67, 821-826. doi:10.4088/JCP.v67n0517

Ko, C. H., Yen, J. Y., Chen, C. S., Yeh, Y. C., \& Yen, C. F. (2009). Predictive values of psychiatric symptoms for internet addiction in adolescents: A 2-year prospective study. Archives of Pediatrics \& Adolescent Medicine, 163, 937-943. doi:10.1001/archpediatrics.2009.159

Ko, C. H., Yen, J. Y., Yen, C. F., Chen, C. S., \& Chen, C. C. (2012). The association between Internet addiction and psychiatric disorder: a review of the literature. European Psychiatry, 27, 1-8. doi:10.1016/j.eurpsy.2010.04.011

Ko, C. H., Yen, J. Y., Yen, C. F., Chen, C. S., Weng, C. C., \& Chen, C. C. (2008). The association between Internet addiction and problematic alcohol use in adolescents: the problem behavior model. CyberPsychology \& Behavior, 11, 571-576. doi:10.1089/cpb.2007.0199

Ko, C. H., Yen, J. Y., Yen, C. F., Lin, H. C., \& Yang, M. J. (2007). Factors predictive for incidence and remission of Internet addiction in young adolescents: A prospective study. CyberPsychology \& Behavior, 10, 545-551. doi:10.1089/cpb.2007.9992

MCIT (2010). Ministry of communication and information technology. Arab republic of Egypt. ICT indicators in brief. www.mcit.gov.eg.

Milani, L., Osualdella, D., \& Di, B. P. (2009). Quality of interpersonal relationships and problematic internet use in adolescence. CyberPsychology \& Behavior, 12, 681-684. doi:10.1089/cpb.2009.0071

Muñoz-Rivas, M. J., Fernández, L., \& Gámez-Guadix, M. (2010). Analysis of the indicators of pathological Internet use in Spanish university students. The Spanish Journal of Psychology, 13, 697-707.

Pallanti, S., Bernardi, S., \& Quercioli, L. (2006). The Shorter PROMIS Questionnaire and the Internet Addiction Scale in the assessment of multiple addictions in a high-school population: prevalence and related disability. CCNS Spectrums, 11, 966-974.

Park, S. K., Kim, J. Y., \& Cho, C. B. (2008). Prevalence of Internet addiction and correlations with family factors among South Korean adolescents. Adolescence, 43, 895-909.

Paul, B., \& Bryant, J. A. (2005). Adolescents and the internet. olescent Medicine Clinics, 16, 413-426.

Shapira, N. A., Goldsmith, T. D., Keck Jr., P. E., Khosla, U. M., \& McElroy, S. L. (2000). Psychiatric features of individuals with problematic Internet use. Journal of Affective Disorders, 57, 267-272. doi:10.1016/S0165-0327(99)00107-X

Sheehan, D. V., Lecrubier, Y., Sheehan, K. H., Amorim, P., Janavs, J., Weiller, E., Hergueta, T., Baker, R., \& Dunbar, G. C. (1998). The Mini International Neuropsychiatric Interview (MINI): The development and validation of a structured diagnostic psychiatric interview for DSM-IV and ICD-10. Journal of Clinical Psychiatry, 59, 22-33.

Siomos, K. E., Dafouli, E. D., Braimiotis, D. A., Mouzas, O. D., \& Angelopoulos, N. V. (2008). Internet addiction among Greek adolescent students. CyberPsychology \& Behavior, 11, 653-657. doi: $10.1089 / \mathrm{cpb} .2008 .0088$

Song, X. Q., Zheng, L., Li, Y., Yu, D. X., \& Wang, Z. Z. (2010). Status of "Internet addiction disorder" (IAD) and its risk factors among first-grade junior students in Wuhan. Chinese Journal of Epidemiol- 


\section{REDA ET AL.}

ogy, 31, 14-17.

Statistical Package of Social Science version 15.0. (2006). Command Syntax Reference 2006. Chicago, IL: SPSS Inc.

UNDP \& INP (2010). Human development report.

http://www.undp.org.eg/Portals/english.pdf

Villella, C., Martinotti, G., Di Nicola, M., Cassano, M., La Torre, G., Gliubizzi, M. D., Messeri, I., Petruccelli, F., Bria, P., Janiri, L., \& Conte, G. (2010). Behavioural addictions in adolescents and young adults: Results from a prevalence study. Journal of Gambling Studies,
27, 203-214. doi:10.1007/s10899-010-9206-0

Widyanto, L., \& Mcmurran, M. (2004). The psychometric properties of internet addiction test. CyberPsychology and Behavior, 7, 443-450. doi:10.1089/cpb.2004.7.443

Young, K. S. (1999). Internet addiction: Symptoms, evaluation, and treatment innovations in clinical practice (Vol. 17). In L. VandeCreek, \& T. L. Jackson (Eds.), Sarasota, FL: Professional Resource Press. 